\title{
Effects of autonomic drugs on contractions of rat seminal vesicles in vivo
}

\author{
J. Hib, R. Ponzio and O. Vilar \\ Centro de Investigaciones en Reproducción, Facultad de Medicina, Paraguay 2155-Piso 10, \\ 1121 Buenos Aires, Argentina
}

\begin{abstract}
Summary. Various autonomic drugs were placed on the peritoneal covering of the seminal vesicles of anaesthetized rats. Adrenaline (which stimulates the $\alpha-, \beta_{1}$ - and $\beta_{2}$ adrenoceptors) and phenylephrine (an $\alpha$-stimulating agent) produced a sudden increase in tonus and in the amplitude and frequency of contractions. Phentolamine (an $\alpha-$ blocker) prevented these effects, whereas propranolol (a $\beta_{1}$ - and $\beta_{2}$-blocker) did not. Phentolamine also abolished the seminal vesicle response to electrical stimulations. Terbutaline ( $\mathrm{a} \beta_{2}$-stimulating agent) did not affect the spontaneous activity. There were no differences between the effects of terbutaline alone and those of terbutaline in the presence of propranolol. Moreover, propranolol did not block the contractile response of the gland to adrenaline or to electrical stimulation. These results indicate that $\alpha-$ adrenergic receptors are present in the muscle cell membrane of the rat seminal vesicle. The effects of acetylcholine were similar to those produced by adrenaline or phenylephrine although of smaller magnitude. Atropine prevented the effects of acetylcholine, indicating that they are of the muscarinic type.
\end{abstract}

\section{Introduction}

In the rat the seminal vesicle glands are well developed but because no ejaculatory ducts are present each seminal vesicle opens directly in the pelvic urethra, separately from the ampulla of the corresponding vas deferens and in close proximity to the urethral orifice of the urinary bladder. Several investigations have demonstrated that the smooth musculature of the seminal vesicles receives an extensive adrenergic innervation, and large accumulations of adrenergic ganglion cells (i.e. short adrenergic neurones) have been found close to or within these accessory sex glands (Falck, Owman \& Sjöstrand, 1965; Sjöstrand, 1965). The short adrenergic neurones are the final link in the sympathetic innervation of the seminal vesicles from the hypogastric nerves (Wakade \& Kirpekar, 1971). Morphological and pharmacological data indicate that seminal vesicles also possess cholinergic innervation (Waddel, 1917; Bacq, 1931; Eliasson \& Risley, 1966; Al-Zuhair, Dixon \& Gosling, 1976). The cholinergic axons reach the glands also via the hypogastric nerves. Cross \& Glover (1958), Saxena (1970) and Karr, Almquist \& Wilson (1973) have shown that stimulation of these nerves resulted in an immediate and vigorous contraction of the seminal vesicles in living animals, similar to those occurring at the moment of physiological emission (Karr \& Almquist, 1973). The same stimulant effect was observed in vitro by Naimzada (1966) and Spedding \& Weetman (1972). The exact role of neurotransmitters at neuroeffector junctions of seminal vesicle smooth muscle during emission has not been well established. Moreover, several authors have reported contradictory results on the type of adrenergic nerve receptors present in this musculature (Guimarães, 1969; Saxena, 1970; Davis, 1971; Holford, 1972; Spedding \& Weetman, 1972; 
Wilson, Almquist \& Karr, 1973; Castelli \& Genedani, 1982). To obtain more accurate knowledge on these subjects, the effects of various autonomic drugs on spontaneous and electrically induced contractions of rat seminal vesicles were studied.

\section{Materials and Methods}

Male Wistar rats, 6 months old and 330-370 g, were used. The animals were fed and caged under standard conditions, separated from female rats. Each rat was anaesthetized with ethyl carbamate (urethane USP; $100 \mathrm{mg} / 100 \mathrm{~g}$ body wt) and accessory sex organs were exposed through a midventral incision in the abdominal wall. To expose the pelvic portion of the urethra, the pubic symphysis was cut and the pubic bones were separated. To record seminal vesicle contractions a small transverse incision in the pelvic urethra was made approximately $1 \mathrm{~cm}$ from the neck of the urinary bladder. A catheter (PE 50 polyethylene tubing; i.d. $0.65 \mathrm{~mm}$, o.d. $0.98 \mathrm{~mm}$; Intramedic, Clay Adams, Parsippany, NJ, U.S.A.) was filled with saline $(0 \cdot 15 \mathrm{M}-\mathrm{NaCl})$ and introduced through the urethral incision. Its tip was brought forward to the proximal end of the urethra until it reached the opening of the excretory ducts of the genital organs. Then, by means of careful probing, it was possible to reach the lumen of one seminal vesicle. The tip of the tube, easily noted through the translucent walls of the organ, was positioned in the middle portion of the gland, close to its convex border. Care was taken not to touch or move the organ at this time. Changes of intraluminal seminal vesicle pressure due to contractility, spontaneous or induced by drugs, were recorded by connecting the catheter to a Sanborn pressure transducer (267 BC). Recordings were made with a Hewlett-Packard preamplifier (model 350-1100) connected to a Hewlett-Packard recorder (7101 BM). The baseline was placed at the centre of the recording paper, and $0.5 \mathrm{~cm}$ of the paper was made equivalent to $1.0 \mathrm{~cm} \mathrm{H}_{2} \mathrm{O}$ of amplitude. Once baseline stability was achieved, the first minutes of spontaneous contractions were registered as the 'control period'. Each drug to be tested, diluted with saline $(0 \cdot 15 \mathrm{M}-\mathrm{NaCl})$, was then topically applied in a volume of $0.01 \mathrm{ml}$ at the urethral end of the cannulated seminal vesicle, where the main vessels of the gland are situated. Recordings were continued for 15-30 min after the application of the following drugs: adrenaline (Sigma Chemical Co., St Louis, MO, U.S.A.), phenylephrine (Sigma), terbutaline (Bricanyl: Astra Pharmaceutical Products, Inc., Worcester, MA, U.S.A.), phentolamine (Regitine: Ciba Pharmaceutical Co., Summit, NJ, U.S.A.), propranolol (Inderal: Imperial Chem. Ind. Ltd, Cheshire, U.K.), acetylcholine (Hoffmann-La Roche, Inc., Nutley, NJ, U.S.A.) and atropine sulphate (Sigma). The pharmacological doses used are given below (see 'Results'). One drug only was used in each animal, except when an agonist was applied $10 \mathrm{~min}$ after a blocking agent. The following characteristics of contractile activity were evaluated: tonus changes $\left(\right.$ as $\left.\mathrm{cm}^{\mathrm{H}} \mathrm{H}_{2} \mathrm{O}\right)$, amplitude (in $\mathrm{cm} \mathrm{H}_{2} \mathrm{O}$ ), and frequency (in contractions/10 min). The significance of changes observed was assessed by Student's $t$ test for paired observations representing the average values of contractility obtained $10 \mathrm{~min}$ before and $10 \mathrm{~min}$ after the administration of each drug. Different experimental groups of animals were used to study the effects of blocking agents (such as phentolamine, propranolol and atropine) on the electrical stimulation of seminal vesicle nerve supply. The electrical stimuli were produced according to the method of Scott \& Dziuk (1959), which we used in previous work (Hib, Ponzio \& Vilar, 1982). The animals received $210-\mathrm{V} / 50-\mathrm{Hz}$ stimulations, which lasted $1 \mathrm{sec}$ each. The first electrical stimulus (considered as 'control') was applied $5 \mathrm{~min}$ before and the second one $5 \mathrm{~min}$ after administration of the blocking drug.

\section{Results}

\section{Spontaneous activity}

The seminal vesicles showed spontaneous activity in all animals. The mean \pm s.e.m. amplitude was $1.8 \pm 0.3 \mathrm{~cm} \mathrm{H}_{2} \mathrm{O}$ and the mean frequency was $24.0 \pm 1.3$ contractions per $10 \mathrm{~min}$ (data from 45 records). 


\section{Adrenaline}

Adrenaline, which stimulates the $\alpha-, \beta_{1}$ - and $\beta_{2}$-adrenoceptors, at a dose of $3 \mathrm{ng}$ produced a rapid rise of the tonus, which reached $12 \cdot 3 \pm 1 \cdot 2 \mathrm{~cm} \mathrm{H}_{2} \mathrm{O}$ above the pre-existing baseline. Also, the amplitude and frequency of contractions showed a significant increase in their values $(P<0.05)$ (Table 1). Then the tone fell slowly, reaching the original level in 11-19 min. At this time also the amplitude and frequency diminished to the pre-test values.

Table 1. Contractile response of rat seminal vesicle to autonomic drugs

\begin{tabular}{|c|c|c|c|c|c|}
\hline Drug & $\begin{array}{c}\text { Dose } \\
\text { (ng) }\end{array}$ & $\begin{array}{l}\text { No. of } \\
\text { animals }\end{array}$ & $\begin{array}{l}\text { Tonus } \\
\text { (cm } \mathrm{H}_{2} \mathrm{O} \text { ) }\end{array}$ & $\begin{array}{c}\text { Amplitude } \\
\text { (cm } \mathrm{H}_{2} \mathrm{O} / \text { contraction) }\end{array}$ & $\begin{array}{c}\text { Frequency } \\
\text { (contractions } / 10 \mathrm{~min} \text { ) }\end{array}$ \\
\hline Adrenaline & 3 & 5 & $+12 \cdot 3 \pm 1 \cdot 2^{*}$ & $+1 \cdot 4 \pm 0.4 *$ & $+7 \cdot 4 \pm 2 \cdot 2^{*}$ \\
\hline Phenylephrine & 10 & 5 & $+13.5 \pm 1.7^{*}$ & $+1.3 \pm 0.3^{*}$ & $+10 \cdot 4+2 \cdot 3^{*}$ \\
\hline Terbutaline & 5 & 5 & - & $-0.5 \pm 0.4$ & $+1.0 \pm 0.8$ \\
\hline Phentolamine & 50 & 10 & - & $+0 \cdot 1 \pm 0 \cdot 1$ & $+1 \cdot 1 \pm 0.7$ \\
\hline Propranolol & 10 & 10 & - & $-0.1 \pm 0.1$ & $+1.2 \pm 1.3$ \\
\hline Acetylcholine & 10 & 5 & $+9.2 \pm 0.5^{*}$ & $+0.5 \pm 0.2^{*}$ & $+7 \cdot 4 \pm 2 \cdot 2^{*}$ \\
\hline Atropine & 20 & 5 & - & $+0.2 \pm 0.2$ & $-2 \cdot 2 \pm 1 \cdot 6$ \\
\hline
\end{tabular}

Values are mean \pm s.e.m. for the difference between values obtained before and after administration of drugs.

* Significantly different from zero $(P<0 \cdot 05)$.

\section{Phenylephrine}

This amine, which has marked $\alpha$ - and weak $\beta_{1}$-adrenoceptor activity, had effects, at $10 \mathrm{ng}$, similar to those of adrenaline (Table 1).

\section{Terbutaline}

Terbutaline, which stimulates almost exclusively the $\beta_{2}$-adrenoceptors, at a dose of $5 \mathrm{ng}$ had no effect on the spontaneous activity of the seminal vesicle $(P>0 \cdot 05)$ (Table 1).

\section{Phentolamine}

Phentolamine, a drug which blocks the $\alpha$-adrenoceptors, had no influence on seminal vesicle contractility when $50 \mathrm{ng}$ were applied $(P>0.05)$ (Table 1). However, this blocker entirely abolished the contractile response of the gland to adrenaline or phenylephrine (Table 2).

Table 2. Contractile response of rat seminal vesicle to autonomic drugs and blockers administered 10 min earlier

\begin{tabular}{llcccc}
\hline \multicolumn{1}{c}{ Drugs } & $\begin{array}{c}\text { Dose } \\
\text { (ng) }\end{array}$ & $\begin{array}{c}\text { No. of } \\
\text { animals }\end{array}$ & $\begin{array}{c}\text { Tonus } \\
\left(\mathrm{cm} \mathrm{H}_{2} \mathrm{O}\right)\end{array}$ & $\begin{array}{c}\text { Amplitude } \\
(\mathrm{cm} \mathrm{H} \mathrm{O} / \text { contraction) }\end{array}$ & $\begin{array}{c}\text { Frequency } \\
\text { (contractions/10 min) }\end{array}$ \\
\hline Phentolamine + adrenaline & $50+3$ & 5 & - & $+0 \cdot 3 \pm 0 \cdot 3$ & $+2 \cdot 2 \pm 1 \cdot 6$ \\
Phentolamine + phenylephrine & $50+10$ & 5 & - & $-0 \cdot 1 \pm 0 \cdot 1$ & $-1 \cdot 2 \pm 1 \cdot 4$ \\
Propranolol + adrenaline & $10+3$ & 5 & $+14 \cdot 0 \pm 1 \cdot 5^{*}$ & $+1 \cdot 3 \pm 0 \cdot 3^{*}$ & $+11 \cdot 6 \pm 2 \cdot 2^{*}$ \\
Propranolol + terbutaline & $10+5$ & 5 & - & $-0 \cdot 2 \pm 0 \cdot 2$ & $+2 \cdot 0 \pm 1 \cdot 3$ \\
Atropine + acetylcholine & $20+10$ & 5 & - & $+0 \cdot 3 \pm 0 \cdot 2$ & $-2 \cdot 2 \pm 1 \cdot 3$ \\
\hline
\end{tabular}

Values are mean \pm s.e.m. for the difference between values obtained before and after administration of drugs.

* Significantly different from zero $(P<0.05)$. 


\section{Propranolol}

Propranolol blocks the $\beta_{1}$ - and $\beta_{2}$-adrenoceptors. A dose of $10 \mathrm{ng}$ did not modify the spontaneous contractility $(P>0.05)$ (Table 1$)$. Moreover, there were no significant differences between the effects of propranolol alone and those of propranolol associated with terbutaline $(P>$ 0.05 ) (Table 2). On the other hand, propranolol did not block the stimulating effects of adrenaline (Table 2).

\section{Acetylcholine}

Acetylcholine $(10 \mathrm{ng})$ caused a sudden increase in tone, amplitude and frequency of contractions $(P<0.05)$. The recorded effects were similar to those produced by adrenaline or phenylephrine although of smaller magnitude (Table 1).

\section{Atropine}

At a dose of $20 \mathrm{ng}$, atropine produced no changes in spontaneous contractility $(P>0.05)$ (Table 1). If given before acetylcholine, atropine prevented the stimulating effects of this agonist agent (Table 2).

\section{Response to electrical stimulation and effects of blocking agents}

In each animal the first (control) electrical stimulation produced a sudden and strong contraction of an amplitude of $25.6 \pm 7.7 \mathrm{~cm} \mathrm{H} \mathrm{H}_{2} \mathrm{O}$ (mean \pm s.e.m. of 15 experiments). Phentolamine prevented the response to a second electrical stimulus applied $5 \mathrm{~min}$ after the administration of the drug. However, the contractions induced by electrical stimulations were not affected by pharmacological blockade with propranolol or atropine $(P>0.05)$.

\section{Discussion}

The fact that contractions induced by electrical stimulation as well as those produced by adrenaline and phenylephrine were blocked by phentolamine (a selective $\alpha$-adrenoceptor antagonist at the dose used) and not by propranolol ( $\mathrm{a} \beta_{1}$-and $\beta_{2}$-adrenergic blocking agent) indicates the presence of $\alpha$-adrenergic receptors in the muscular cell membrane of the rat seminal vesicle. In contrast, these experiments suggest the lack of $\beta_{1}$-adrenergic receptors in the gland. If $\beta_{1}$-adrenoceptors are present, it should be reasonable to expect the $\beta_{1}$-stimulating activity of adrenaline to be evident when the $\alpha$-stimulating activity was blocked by an $\alpha$-blocking agent such as phentolamine. Moreover, since no significant changes in the spontaneous contractility were produced by the $\beta_{2}$ adrenergic stimulating agent terbutaline, the muscle of the rat seminal vesicles seems to be devoid of $\beta_{2}$-adrenergic receptors. These results are in accord with those reported by Guimarães (1969), Davis (1971), Holford (1972) and Castelli \& Genedani (1982) from in-vitro pharmacological studies of contractility of rat and guinea-pig seminal vesicles. Rabbit seminal vesicle musculature also exhibits $\alpha$-adrenergic receptors (Wilson et al., 1973). However, our results in the anaesthetized rat do not support the findings of Saxena (1970) and Spedding \& Weetman (1972), who reported that $\beta_{2}$-adrenoceptors are present in guinea-pig seminal vesicles. In our study, seminal vesicle contractility was stimulated by acetylcholine, adrenaline and phenylephrine. Since atropine antagonized the effects produced by acetylcholine, the action of this cholinergic agent is of the muscarinic type. It is well known that in the smooth muscle of other organs the effects mediated by parasympathetic receptors are opposite to those mediated by sympathetic ones. Nevertheless, in the smooth musculature of the male accessory sexual organs both types of autonomic agents, para- 
sympathomimetics and sympathomimetics, have shown the same stimulatory effect (Waddel, 1917; Eliasson \& Risley, 1966; Hib, 1976; Agostini, Borda, Gimeno \& Gimeno, 1981). The exact role of neurotransmitters at the neuroeffector junctions during emission is not well understood, but there is strong evidence that noradrenaline could act as the principal motor transmitter and acetylcholine would contribute to the regulation of this activity. Based on morphological evidence, Dixon \& Gosling (1972) suggested an axo-axonal rather than a neuromuscular influence for the cholinergic nerve terminals in the dual innervation (adrenergic and cholinergic) of the rat vas deferens. This hypothesis has been supported by the pharmacological studies of Agostini et al. (1981) who suggested that acetylcholine might induce an indirect action involving the release of noradrenaline at presynaptic sites. In addition, our results showed that the $\alpha$-adrenoceptor antagonist drug phentolamine blocks the contractions induced by electrical stimuli, but these responses appeared to be resistant to blockade by atropine. This is compatible with the suggestion that the action of acetylcholine would be to modulate the noradrenaline release at adrenergic nerve terminals.

In preliminary experiments excessively high doses were required when some drugs were intravenously administered to attain any response of the seminal vesicle musculature at all, but this was also accompanied by a severe cardiorespiratory stress resulting in the death of several animals. The poor effectiveness of pharmacological doses when intravenous administration was used may have been due to the drugs being present in insufficient quantities at the receptor sites. Since the drugs did not depend on the general blood supply for their access to the seminal vesicle muscle when they were applied topically on the peritoneal covering of the base of the gland, a more effective action was obtained because the pharmacological agents were directly absorbed and could reach the synapsis contacts in adequate concentrations. In other preliminary studies smaller and larger doses of locally applied drugs were used. Some drugs did not show any effects at lower concentrations, but higher levels affected the recovery of seminal vesicle spontaneous activity.

The rat seminal vesicles not only responded to autonomic drugs and to electrical stimulation but also showed spontaneous rhythmic contractions. The data provided by previous workers on spontaneous contractility are in many cases contradictory. For example, while several authors have registered this activity in seminal vesicles of intact males (Waddel, 1917; Cross \& Glover, 1958; Melin, 1970), others reported that the seminal vesicles are quiescent (Martins \& Valle, 1939; Grunt, Knisely \& Berry, 1956; Grunt, Walker \& Higgins, 1960; Eliasson \& Risley, 1966). Moreover; according to some of the latter authors, the glands only contract spontaneously when androgens are absent. Since spontaneous contractions were not affected by the blocking agents used in our studies, it is reasonable to suppose that this activity is either not neurally mediated or it is supported by as yet unknown neurotransmitters.

This work was supported by CONICET, Argentina. J.H. and O.V. are investigators of the Consejo Nacional de Investigaciones Científicas y Técnicas de la República Argentina. We thank Mrs Lucila Neremberg for technical help.

\section{References}

Agostini, M.C., Borda, E.S., Gimeno, M.F. \& Gimeno, A.L. (1981) Differences in the effects of acetylcholine on the vas deferens from normal and castrated rats. A participation of adrenergic mechanisms. Archs int. Pharmacodyn. Thér. 250, 212-220.

Al-Zuhair, A.G.H., Dixon, J.S. \& Gosling, J.A. (1976) Studies on the autonomic innervation of the guineapig seminal vesicle and ductus deferens. J. Physiol., Lond. 257, $9 P-11 P$.
Bacq, Z.M. (1931) Impotence of the male rodent after sympathetic denervation of the genital organs. Am.J. Physiol. 96, 321-330.

Castelli, M. \& Genedani, S. (1982) Phentolamine inhibition of rat seminal vesicle response to dopaminemimetic drugs: $\alpha$-adrenoceptor implication or lack of specificity? J. Pharm. Pharmac. 34, 331-333.

Cross, B.A. \& Glover, T.D. (1958) The hypothalamus and seminal emission. J. Endocr. 16, 385 395. 
Davis, W.G. (1971) The reversal of phenoxybenzamineproduced $\alpha$-adrenoceptor blockade by the isomers of propranolol and INPEA. J. Pharm. Pharmac. 23, 332-338.

Dixon, J.S. \& Gosling, J.A. (1972) The distribution of autonomic nerves in the musculature of the rat vas deferens. A light and electron microscope investigation. J. comp. Neurol. 146, 175-188.

Eliasson, R. \& Risley, P.L. (1966) Potentiated response of isolated seminal vesicles to catecholamines and acetylcholine in the presence of $\mathrm{PGE}_{1}$. Acta physiol. scand. 67, 253-254.

Falck, B., Owman, Ch. \& Sjöstrand, N.O. (1965) Peripherally located adrenergic neurons innervating the vas deferens and the seminal vesicle of the guinea-pig. Experientia 21, 98-100.

Grunt, J.A., Knisely, W.H. \& Berry, R.J. (1956) In vivo observations on the seminal vesicles of intact, castrated and hormonally treated rats. Endocrinology 59, 540-547.

Grunt, J.A., Walker, J.E. \& Higgins, J.T. (1960) Effects of intravenous steroids on seminal vesicle contractions of castrated rats. Am. J. Physiol. 198, 754-756.

Guimarães, S. (1969) Reversal by pronethanol of dibenamine blockade: a study on the seminal vesicle of the guinea-pig. Br. J. Pharmac. 36, 594-601.

Hib, J. (1976) Effects of autonomic drugs on epididymal contractions. Fert. Steril. 27, 951-956.

Hib, J., Ponzio, R. \& Vilar, O. (1982) Contractility of the rat cauda epididymidis and vas deferens during seminal emission. J. Reprod. Fert. 66, 47-50.

Holford, N.H.G. (1972) Antagonism of some spasmogens of the rat seminal vesicle. Br. J. Pharmac. 46, 522P, Abstr.

Karr, J.P. \& Almquist, J.O. (1973) A new technique for in vivo measurement of accessory sex organ activity in male rabbits. J. Anim. Sci. 36, 554-562.
Karr, J.P., Almquist, J.O. \& Wilson, L.F. (1973) Measurement of vas deferens and seminal vesicle contractions in the anesthetized rabbit. J. Anim. Sci. 37, 758-761.

Martins, T. \& Valle, J.R. (1939) Endocrine control of the motility of the male accessory genital organs. Endocrinology 25, 80-90.

Melin, P. (1970) In-vivo recording of contractile activity of male accessory genital organs in rabbits. Acta physiol. scand. 79, 109-113.

Naimzada, M.K. (1966) Response of the guinea-pig isolated seminal vesicle to stimulation of the hypogastric nerve. Med. Pharmac. exp. 15, 561-567.

Saxena, P.R. (1970) Effect of some drugs on the responses of the vas deferens and seminal vesicle to hypogastric nerve stimulation in the guinea-pig in vivo. Pharmacology, Basel 3, 220-228.

Scott, J.V. \& Dziuk, P.J. (1959) Evaluation of the electro-ejaculation technique and spermatozoa thus obtained from rats, mice and guinea pigs. Anat. Rec. 133, 655-664.

Sjöstrand, N.O. (1965) The adrenergic innervation of the vas deferens and accessory male genital glands. Acta physiol. scand., Suppl. 257, 1-82.

Spedding, M. \& Weetman, D.F. (1972) The presence of $\beta$ adrenoceptors in the guinea-pig seminal vesicle. $B r$. J. Pharmac. 45, 21-28.

Waddel, J.A. (1917) The pharmacology of the seminal vesicles. J. Pharmac. exp. Thér. 9, 113-120.

Wakade, A.R. \& Kirpekar, S.M. (1971) Chemical and histochemical studies on the sympathetic innervation of the vas deferens and seminal vesicle of the guineapig. J. Pharmac. exp. Ther. 178, 432-441.

Wilson, L.F., Almquist, J.O. \& Karr, J.P. (1973) Effect of alpha adrenergic drugs on contractility of the rabbit seminal vesicle. J. Anim. Sci. 37, 558-561. 